\title{
ANALISA KEBUTUHAN SATUAN RUANG PARKIR GIANT EXTRA DEPART. STORE DI JL AP. PETTARANI KOTA MAKASSAR
}

(Analysis Needs Parking Space Giant Extra Depart. Store in jl AP. Pettarani Kota Makassar)

\author{
R. Awal R ${ }^{1}$, Lambang Basri Said ${ }^{2}$, St. Maryam $\mathbf{H}^{3}$ \\ 1 PPK Bendungan 3, SNVT Pembangunan Bendungan BBWS Pompengan Jeneberang . \\ Jalan Sekolah Guru Perawat No. 33 Makassar, 085255788184, rabiulawal_ramli@yahoo.com \\ ${ }^{2}$ Dosen Jurusan Teknik Sipil Universitas Muslim Indonesia (UMI) \\ Jalan Urip Sumoharjo No.225 Makassar, Telp. 454534 \\ ${ }^{3}$ Dosen Jurusan Teknik Sipil Universitas Muslim Indonesia (UMI) \\ Jalan Urip Sumoharjo No.225 Makassar, Telp. 454534
}

\begin{abstract}
Abstrak
kurangnya pengetahuan serta tidak adanya kesadaran tentang tata cara parkir mengakibatkan pengaturan kendaraan masih dilakukan sepenuhnya oleh pemilik kendaraan. Keadaan tersebut berpengaruh terhadap tingkat kelancaran pelayanan pada jalan di depan Giants Pettarani. Namun pada suatu pusat perbelanjaan, pengaturan kendaraan dilakukan oleh Pengelola. Maka ketersediaan ruang untuk parkir sangat perlu di tata dengan sebaik-baiknya agar ketersediaan lahan tersebut dapat dimanfaatkan semaksimal mungkin karena parkir yang kurang nyaman seringkali menjadi sebab digunakannya badan jalan (on street) sebagai ruang untuk parkir dan tentunya menimbulkan masalah keselamatan dan kemacetan karena menutup satu atau dua buah lajur, mempersempit ruang jalan, dan mengurangi jarak pandang Pengendara. Penelitian ini bersifat deskriptif dengan analisis kuantitatif merupakan jenis studi kasus dengan survey dan observasi langsung di lapangan guna mengetahui satuan ruang parkir Giants Extra Dept. Store di JL AP Pettarani Kota Makassar. Hasil penelitian menunjukkan karakteristik parkir : volume puncak sebesar 920, akumulasi parkir kumulatif sebesar 54, durasi parkir kumulatif selama 9 jam 40 menit, rata-rata durasi parkir selama 2 jam 35 menit, pergantian parkir pada basemen area sebesar 0.29 dan untuk pelataran parkir roda dua sebesar 0.2 dan jumlah ruang parkir yang dibutuhkan untuk sepeda motor sebanyak 17 ruang dengan indeks parkir kumulatif sebesar 0.081081 dan dapat disimpulkan bahwa area parkir sekarang masih dapat menampung kendaraan parkir. Hal ini ditunjukkan bahwa area parkir yang tersedia seluas $2016 \mathrm{~m}^{2}>$ area parkir yang digunakan yakni $1232,5 \mathrm{~m}^{2}$.
\end{abstract}

Kata kunci : Satuan Ruang Parkir, Pusat Perbelanjaan, karakteristik parkir.

\section{PENDAHULUAN}

\subsection{Latar Belakang}

Kota Makassar merupakan salah satu pusat dari berbagai macam kegiatan di Indonesia Timur. Salah satu indikator yang bisa kita lihat adalah banyaknya pusat-pusat perbelanjaan yang dibangun sehingga mobilitas masyarakat Kota Makassar makin tinggi dari waktu ke waktu. Hal ini menuntut pemerintah menyediakan sarana dan prasarana yang lebih baik. Berdasarkan kondisi diatas, secara tidak langsung membuat daerah-daerah komersil di Kota Makassar menjadi salah satu tujuan utama para masyarakat yang akan melakukan aktifitas. 
Setiap pusat perbelanjaan yang ada membutuhkan ruang untuk parkir : ini adalah sebuah isu kunci di hampir semua Kota. Mobil yang sedang parkir membutuhkan sekurang-kurangnya $8 \mathrm{~m}^{2}$ dan seringkali lebih dari itu untuk ruang bermanuver. Suatu kebutuhan yang sangat besar terutama di wilayah perkotaan yang padat dimana harga lahan kini sangat tinggi. Seringkali, mobil mendapatkan ruang untuk parkir yang lebih besar dari ruang untuk manusia bermukim. Dan itulah salah satu permasalahan yang dihadapi oleh pengelola di hampir semua pusat perbelanjaan yang ada pada umumnya, dan di Giants Pettarani pada khususnya.

Dari hasil pengamatan secara visual dilapangan diperoleh gambaran bahwa Penggunaan pola parkir yang digunakan oleh Pengelola untuk kendaraan roda empat dan roda dua ialah $90^{\circ}$ dan tentunya cukup banyak membutuhkan ruang. dan jika ada acara besar seperti Hari Libur Lebaran, even musik ataupun promo produk yang membuat banyak pengunjung berdatangan mengakibatkan pola parkir tersebut sudah tidak teratur.

Dari fenomena diatas, dapat dinyatakan bahwa perlunya merumuskan bagaimana pola parkir yang baik secara teknis dan ketersediaan ruang untuk parkir agar dapat mengurangi jumlah pengguna parkir di badan jalan (on street) atau bahkan meniadakannya.

\subsection{Rumusan Masalah}

Berdasarkan latar belakang maka rumusan masalah dari penulisan Tesis ini yaitu :

1. Bagaimana karakteristik parkir pada Giants Pettarani Depart. Store Pettarani?

2. Bagaimana pola parkir yang baik secara teknis dan ketersediaan ruang untuk parkir termanfaatkan secara efektif pada Giants Pettarani Depart. Store Pettarani?

\subsection{Tujuan Penelitian}

Tujuan Penulisan Tesis ini adalah :

1. Menganalisis karakteristik parkir pada Giants Pettarani Depart. Store Pettarani

2. Menganalisis pola parkir yang baik secara teknis dan ketersediaan ruang untuk parkir termanfaatkan secara efektif pada Giants Pettarani Depart. Store Pettarani

\section{METODE PENELITIAN}

\subsection{Jenis Penelitian dan Metode Survei}

Penelitian ini bersifat deskriptif dengan analisis kuantitatif merupakan jenis studi kasus dengan survey dan observasi langsung di lapangan guna mengetahui satuan ruang parkir Giants Extra Dept. Store di JL AP Pettarani Kota Makassar.

\subsection{Waktu dan Lokasi Penelitian}

Penelitian dilaksanakan \pm 2 (dua) bulan. Yakni bulan November - Desember 2018. Lokasi Penelitian berada pada JL. AP. Pettarani Kota Makassar.

\subsection{Teknik Pengumpulan Data}

\section{Data Primer}

a. Data Volume Parkir

Data volume parkir adalah data yang dikumpulkan dari hasil pengamatan langsung mulai dari pukul 09.00 hingga pukul 00.00 untuk mendapatkan data yang riil mengenai volume parkir. Kegiatan yang dilakukan adalah pencatatan dan pendokumentasian kegiatan. 
b. Data Kapasitas Parkir

Data kapasitas parkir adalah data yang dikumpulkan dari hasil pengukuran luas area parkir yang disediakan oleh pengelola untuk mendapatkan data yang riil mengenai kapasitas maksimum parkir.

\section{Data Sekunder}

Data sekunder adalah data yang diperoleh secara tidak langsung, misalnya studi pustaka dimana kegiatan ini untuk melengkapi data yang didapatkan dari hasil pencatatan langsung dilapangan. Kegiatan ini dilakukan melalui jurnal-jurnal, buku-buku, tugas akhir, dan literature lainnya yang berkaitan dengan topic yang dibahas untuk menambah kelengkapan data serta analisis yang dilakukan.

\subsection{Analisis Data}

Data yang terkumpul dari hasil pengamatan akan dianalisa dan akan diperoleh hasil satuan ruang parkir Giants Pettarani Dept. Store di JL AP. Pettarani Kota Makassar. Data yang diperoleh meliputi:

a. Volume, kendaraan yang masuk dan keluar area parkir. dalam hitungan ini akan dihitung secara manual.

b. Kapasitas ruang parkir, dimana kapasitas parkir akan dihitung dengan Manual Kapasitas Jalan Indonesia (MKJI) 1997 sebagai acuan.

\section{Karakteristik Parkir}

a. Volume Parkir

b. Akumulasi Parkir

c. Lama Waktu Parkir (Durasi)

d. $\quad$ Tingkat Pergantian Parkir (Turn Over Parking)

e. Kapasitas Parkir

f. Penyediaan Parkir

g. Indeks Parkir

h. Kebutuhan Ruang Parkir

2. Dimensi Kendaraan dan Satuan Ruang Parkir

\section{ANALISIS DATA}

\subsection{Karakteristik Parkir}

\section{Volume Parkir}

Dalam pengambilan data jumlah kendaraan parkir dibedakan atas beberapa jenis kendaraan mulai dari tiba hingga meninggalkan tempat parkir. Jumlah kendaraan parkir diambil mulai dari pukul 09.00 hingga pukul 00.00. adapun hasil pengamatan jumlah kendaraan parkir dan waktu parkir di GIANTS PETTARANI. Dari hasil pengamatan disimpulkan bahwa kendaraan parkir terbanyak ialah sepeda motor sebanyak 866 kendaraan dengan jumlah keseluruhan kendaraan parkir sebanyak 920 kendaraan pada hari jam puncak Rabu 13 Februari 2019. Pemanfaatan parkir untuk kendaraan bermotor roda empat dan kendaraan bermotor roda dua keseluruhan menggunakan sudut parkir $90^{\circ}$ dari data pengamatan.

\section{Akumulasi Parkir}

Akumulasi Parkir yaitu jumlah kendaraan yang parkir di suatu tempat pada waktu 
tertentu, dan dapat dibagi sesuai dengan kategori jenis maksud perjalanan. Diambil waktu puncak yakni 13 februari 2019 ;

$$
\begin{aligned}
\text { Akumulasi Parkir } & =\mathrm{Ei}-\mathrm{Ex} \\
& =51-0 \quad=51
\end{aligned}
$$

(hasil selanjutnya dapat dilihat pada table 29)

Tabel 29. Hasil Pengamatan Survey kendaraan masuk - kendaraan keluar ruang parkir

\begin{tabular}{|c|c|c|c|}
\hline Waktu & Masuk $(\mathrm{Ei})$ & Keluar $(\mathrm{Ex})$ & Akumulasi $(\mathrm{Ei}-\mathrm{Ex})$ \\
\hline $09.00-10.00$ & 51 & 0 & 51 \\
$10.00-11.00$ & 27 & 0 & 27 \\
$11.00-12.00$ & 5 & 12 & -7 \\
$12.00-13.00$ & 0 & 15 & -12 \\
$13.00-14.00$ & 19 & 0 & 19 \\
$14.00-15.00$ & 18 & 5 & 23 \\
$15.00-16.00$ & 126 & 9 & 122 \\
$16.00-17.00$ & 68 & 11 & 62 \\
$17.00-18.00$ & 186 & 107 & 87 \\
$18.00-19.00$ & 106 & 8 & 105 \\
$19.00-20.00$ & 119 & 35 & 98 \\
$20.00-21.00$ & 129 & 167 & -37 \\
$21.00-22.00$ & 12 & 239 & -226 \\
$22.00-23.00$ & 0 & 256 & -256 \\
$23.00-00.00$ & 0 & 2 & -2 \\
\hline Total & 866 & 866 & 0 \\
\hline Rata-rata & 57.73 & 57,73 & 0 \\
\hline
\end{tabular}

\section{Sumber : Hasil Analisis}

\section{Lama Waktu Parkir (Durasi)}

Durasi parkir berdasarkan rata-rata waktu parkir sebuah kendaraan disuatu tempat dalam satu satuan waktu. Durasi parkir diperoleh dari lama kendaraan berada dalam ruang parkir yaitu dengan mengambil sampel dari masing-masing kendaraan yang beroperasi kemudian dirata-ratakan seperti yang tercantum dalam table 30 sebagai berikut ;

$$
\begin{aligned}
\text { Durasi } & =\text { Extime }- \text { Entime } \\
& =\text { pukul } 16.16-\text { pukul } 09.00 \\
& =436 \text { menit }
\end{aligned}
$$

Tabel 30. Tabel Durasi Parkir

\begin{tabular}{|l|c|}
\hline \multicolumn{1}{|c|}{ Jenis Kendaraan } & $\begin{array}{c}\text { Durasi Parkir pada waktu puncak } \\
\text { sabtu (menit) }\end{array}$ \\
\hline Mobil Pribadi & 78 \\
\hline Pick up & 50 \\
\hline Bus & 0 \\
\hline Sepeda Motor & 436 \\
\hline
\end{tabular}

Sumber : Hasil Analisis

\section{Pergantian Parkir (Turnover Parking)}

Pergantian parkir adalah tingkat penggunaan ruang parkir dan diperoleh dengan membagi volume parkir dengan jumlah ruang parkir untuk satu periode tertentu. Dalam hal ini digunakan waktu puncak pada hari rabu 13 februari 2019. Untuk sepeda motor Tingkat 
turnover sebesar 0.97, Untuk pelataran kendaraan roda empat dibagi atas beberapa golongan yakni untuk Mobil penumpang Golongan I berupa mobil pribadi Tingkat turnover sebesar 0.97, Mobil Penumpang Golongan III berupa pick up Tingkat turnover sebesar 0.01, sedangkan Tingkat turnover untuk Bus/Truck adalah 0.

\section{Rata-Rata Durasi Parkir Keseluruhan}

$$
\begin{aligned}
\mathrm{D}=\frac{\sum_{i=n}^{n} d i}{n} & =((78+50+0+436) / 4) \\
& =141 \text { Menit }(2 \text { jam } 35 \text { menit })
\end{aligned}
$$

\section{Indeks Parkir}

Indeks Parkir $=(($ akumulasi parkir/ruang parkir tersedia $) \times 100 \%)$

$=((51: 192) \times 100 \%)$

$=26.56$ (hasil selanjutnya lihat tabel 31)

Tabel 31. Indeks Parkir

\section{Sumber : Hasil Analisis}

\begin{tabular}{|c|c|c|c|}
\hline Waktu & $\begin{array}{c}\text { Akumulasi } \\
\text { (Ei-Ex) }\end{array}$ & tersedia & indeks (\%) \\
\hline $09.00-10.00$ & 51 & & 26.56 \\
\hline $10.00-11.00$ & 27 & & 14.06 \\
\hline $11.00-12.00$ & -7 & & -3.65 \\
\hline $12.00-13.00$ & -15 & & -7.81 \\
\hline $13.00-14.00$ & 18 & & 9.38 \\
\hline $14.00-15.00$ & 14 & \multirow{5}{*}{192} & 7.29 \\
\hline $15.00-16.00$ & 117 & 60.94 \\
\hline $16.00-17.00$ & 57 & & 29.69 \\
\hline $17.00-18.00$ & 79 & 41.15 \\
\hline $18.00-19.00$ & 98 & 51.04 \\
\hline $19.00-20.00$ & 84 & & 43.75 \\
\hline $20.00-21.00$ & -38 & & -19.79 \\
\hline $21.00-22.00$ & -227 & & -118.23 \\
\hline $22.00-23.00$ & -256 & & -133.33 \\
\hline $23.00-00.00$ & -2 & & -1.04 \\
\hline
\end{tabular}

\section{Desain Pola Parkir Terhadap Kapasitas Maksimum Ruang Parkir}

a). Untuk Mobil Penumpang Golongan I

1. Untuk Pola Parkir Paralel $0^{0}$

Kapasitas $\quad=($ Luas Area Parkir / SRP $)$

$$
=1728 / 5.3
$$

$=\mathbf{3 2 6}$ Kendaraan

2. Untuk Pola Parkir Menyudut $30^{\circ}$

3. Untuk Pola Parkir Menyudut $45^{0}$

$=1728 / 7.60$

$=\mathbf{2 2 7}$ Kendaraan

4. Untuk Pola Parkir Menyudut $60^{\circ}$

$=1728 / 9.30$

$=\mathbf{1 8 6}$ Kendaraan

5. Untuk Pola Parkir Menyudut $90^{\circ}$

$=1728 / 10.55$

$=164$ Kendaraan

$=1728 / 11.2$ 
$=\mathbf{1 5 4}$ Kendaraan

b). Untuk Kendaraan Penumpang Golongan II

a. Untuk Pola Parkir Paralel $0^{\circ}$

Kapasitas $\quad=($ Luas Area Parkir / SRP $)$

$=1728 / 5.5$

$=314$ Kendaraan

1. Untuk Pola Parkir Menyudut $30^{\circ}=1728 / 7.75$

$=\mathbf{2 2 3}$ Kendaraan

2. Untuk Pola Parkir Menyudut $45^{\circ} \quad=1728 / 9.35$

3. Untuk Pola Parkir Menyudut $60^{\circ} \quad=1728 / 10.55$

$=164$ Kendaraan

4. Untuk Pola Parkir Menyudut $90^{\circ}=1728 / 11.2$

$=\mathbf{1 5 4}$ Kendaraan

c). Untuk Kendaraan Penumpang Golongan III

a. Untuk Pola Parkir Paralel $0^{0}$

Kapasitas $\quad=($ Luas Area Parkir/ SRP $)$

$=1728 / 6$

$=\mathbf{2 8 8}$ Kendaraan

b. Untuk Pola Parkir Menyudut $30^{\circ}=1728 / 7.90$

$=219$ Kendaraan

c. Untuk Pola Parkir Menyudut $45^{0}=1728 / 9.45$

d. Untuk Pola Parkir Menyudut $60^{\circ} \quad \begin{array}{ll} & \\ & =1728 / 10.60\end{array}$

e. Untuk Pola Parkir Menyudut $90^{\circ} \quad \begin{array}{ll} & =163 \text { Kendar } \\ & =1528 / 11.2\end{array}$

d). Sepeda Motor

$=\mathbf{1 5 4}$ Kendaraan

\subsection{Prediksi 10 Tahun}

$$
\begin{aligned}
\text { Kapasitas } & =(\text { Luas Area Parkir / SRP }) \\
& =288 / 1.5 \\
& =192 \text { Kendaraan }
\end{aligned}
$$

Dari data perparkiran yang telah diperoleh dapat dihitung perkiraan jumlah arus kendaraan saat ini dan untuk periode lima tahun mendatang. Analisis ini berguna untuk mengetahui apakah kapasitas parkir yang ada sekarang ini dapat menampung kendaraan yang diprediksikan masuk ke area parkir pada tahun - tahun mendatang. Adapun persamaan untuk menentukan perkiraan penggunaan ruang parkir yang akan terjadi pada tahun-tahun berikutnya adalah sebagai berikut :

$$
P=P o(1+i)^{n}
$$

Dimana : $\quad \mathrm{P}=$ Jumlah kendaraan pada tahun ke-n

Po $=$ Jumlah kendaraan pada tahun awal

$\mathrm{I}=$ Tingkat petumbuhan kendaraan

$\mathrm{N}=$ Waktu (tahun)

Setelah data parkir pada tahun 2018 diketahui, kemudian dilakukan prediksi yang akan terjadi pada 10 tahun mendatang. Dari Rencana Umum Tata Kota (RUTK) diketahui bahwa tingkat pertumbuhan kendaraan rata-rata di Kota Makassar adalah sebesar $10 \%$. Setelah data kendaraan untuk 10 tahun mendatang didapat kemudian dibandingkan dengan kapasitas parkir yang ada sehingga didapatkan derajat kejenuhan.

Dari derajat kejenuhan ini dapat dikategorikan apakah kapsitas parkir tersebut masih memenuhi. Prediksi perparkiran dengan tingkat pertumbuhan kendaraan rata-rata 
sebesar $10 \%$ per-tahun pada GIANTS PETTARANI dapat di tunjukkan pada tabel dibawah ini, bahwa untuk lima tahun mendatang penggunaan lahan parkir tersebut mengalami masalah karena kapasitas parkir yang ada hampir tidak bisa menampung kendaraan yang akan parkir.

Contoh perhitungan untuk kondisi eksisting 2019:

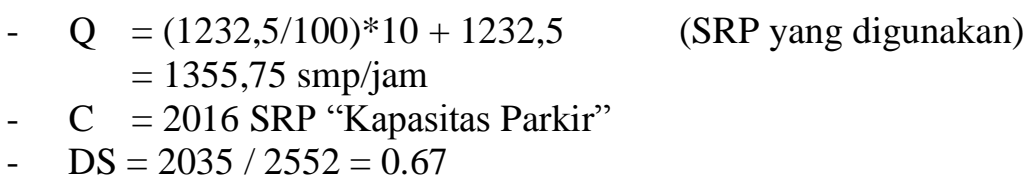

Tabel 32. Prediksi penggunaan ruang untuk parkir Kondisi Eksisting (Tahun 2019) dan 10 Tahun Mendatang.

\begin{tabular}{|c|c|c|c|}
\hline Tahun & $\begin{array}{c}\text { SRP } \\
\text { DIGUNAKAN }\end{array}$ & $\begin{array}{c}\text { SRP } \\
\text { TERSEDIA }\end{array}$ & PREDIKSI \\
\hline 2019 & 1232.5 & 2016 & 1355.8 \\
\hline 2020 & 1355.8 & 2016 & 1491.3 \\
\hline 2021 & 1491.3 & 2016 & 1640.5 \\
\hline 2022 & 1640.5 & 2016 & 1804.5 \\
\hline 2023 & 1804.5 & 2016 & 1985.0 \\
\hline 2024 & 1985.0 & 2016 & 2183.4 \\
\hline 2025 & 2183.4 & 2016 & 2401.8 \\
\hline 2026 & 2401.8 & 2016 & 2642.0 \\
\hline 2027 & 2642.0 & 2016 & 2906.2 \\
\hline 2028 & 2906.2 & 2016 & 3196.8 \\
\hline 2029 & 3196.8 & 2016 & 3516.5 \\
\hline
\end{tabular}

Sumber : Hasil Analisis

Pada Tabel 32. Terlihat bahwa pada tahun 2026 kapasitas parkir telah mengalami overload.

\subsection{Pembahasan}

Setelah dilakukan analisa data terlihat bahwa petak parkir di GIANTS PETTARANI umumnya masih bisa menampung kendaraan parkir, baik untuk jenis kendaraan mobil pribadi, bus, pick up ataupun sepeda motor. Hal ini ditunjukkan bahwa area parkir sekarang masih dapat menampung kendaraan parkir. Hal ini ditunjukkan bahwa area parkir yang tersedia seluas $2016 \mathrm{~m}^{2}>$ area parkir yang digunakan yakni 1232,5 $\mathrm{m}^{2}$.

Adapun penerapan kebijakan perparkiran pada GIANTS PETTARANI dapat diterapkan sebagai berikut :

1. Pengelolaan teknis yang baik dalam mengelola parkir. Maksud dari pengelolaan teknis yang baik disini adalah penataan kendaraan dalam parkir. Masih banyak ditemui kendaraan yang parkir di kawasan ini secara sembarangan atau tidak pada ruang parkir yang disediakan.

2. Penambahan area parkir. Berdasarkan analisis yang telah dilakukan dengan didasarkan pada kondisi eksiting di lapangan ternyata ruang parkir yang sudah tersedia telah memenuhi dengan pengguna yang ada. Mungkin untuk satu atau dua tahun ke depan masih memadai, namun untuk tahun 2026 mungkin perlu adanya pembenahan dengan melihat pertambahan jumlah jumlah penduduk, pertumbuhan 
kendaraan, dan pengunjung GIANTS PETTARANI yang setiap tahun selalu bertambah yang mungkin akan diimbangi dengan penggunaan kendaraan roda 2 maupun kendaraan roda 4 sebagai sarana tansportasi di GIANTS PETTARANI yang meningkat. Maka dari itu perlu penambahan area parkir untuk mengatasi kekurangan dari ruang parkir yang ada.

3. Dilakukan perubahan sistem tarif parkir yang ada saat ini, pihak GIANTS PETTARANI harus menaikan tarif parkir yang lebih besar dan diberlakukan tarif perjam, sehingga kendaraan yang memiliki waktu parkir lama akan mengubah kebiasaan parkirnya lebih singkat. Sehingga pemanfaatan/pengguna fasilitas parkir dapat termanfaatkan seefisien mungkin.

4. Untuk kedepan tenaga kerja/karyawan GIANTS PETTARANI harus dikenai tarif parkir yang yang mana selama ini tenaga kerja/karyawan tidak dikenai biaya parkir sedikitpun. Dengan begitu para tenaga kerja/karyawan berpikir dua kali untuk memakai kendaraan pribadi pergi bekerja. Atau para tenaga kerja/karyawan diharuskan mengurangi membawa kendaraan.

\section{KESIMPULAN}

Dengan melihat hasil perhitungan analisis masalah yang terjadi terhadap parkir pada pada pusat perbelanjaan GIANTS PETTARANI, dapat ditarik kesimpulan bahwa :

1. Dari hasil analisa pada pusat perbelanjaan GIANTS PETTARANI didapatkan karakteristik parkir : volume puncak sebesar 920, akumulasi parkir kumulatif sebesar 54, durasi parkir kumulatif selama 9 jam 40 menit, rata-rata durasi parkir selama 2 jam 35 menit, pergantian parkir pada basemen area sebesar 0.29 dan untuk pelataran parkir roda dua sebesar 0.2 dan jumlah ruang parkir yang dibutuhkan untuk sepeda motor sebanyak 17 ruang dengan indeks parkir kumulatif sebesar 0.081081 .

2. Dari hasil pengamatan disimpulkan bahwa area parkir sekarang masih dapat menampung kendaraan parkir. Hal ini ditunjukkan bahwa area parkir yang tersedia seluas $2016 \mathrm{~m}^{2}>$ area parkir yang digunakan yakni $1232,5 \mathrm{~m}^{2}$.

3. Penggunaan pola parkir $90^{\circ}$ terbukti membutuhkan ruang yang cukup besar, hal ini dapat dibuktikan dari hasil analisis hanya mampu menampung kendaraan sebanyak 154 unit saja. Berbeda dengan sudut parkir parallel yang mampu menampung kendaraan hingga 326 unit

\section{SARAN}

Untuk menghindari terjadinya volume parkir mendekati titik jenuh dan menjadi buruknya tingkat kinerja ruang parkir di GIANTS PETTARANI. Maka perlu dilakukan langkah - langkah untuk meningkatkan kapasitas dan tingkat pelayanan parkir pada pusat perbelanjaan GIANTS PETTARANI adalah sebagai berikut :

1. Jika kedepannya kapasitas ruang tak lagi memadai sebaiknya pola parkir $0^{0}$ atau parkir paralel diberlakukan karena mampu menampung jumlah kendaraan lebih banyak ketimbang pola parkir $90^{\circ}$.

2. Sehubungan dengan letak lokasi di jalan primer maka perlu PEMKOT memperketat aturan kendaraan yang parkir ataupun singgah di badan jalan didepan GIANTS PETTARANI.

3. Agar parkir tidak semrawut, disarankan agar ditambahkan rambu-rambu sebagai petunjuk jenis kendaraan parkir.

\section{UCAPAN TERIMA KASIH}

Dalam pembuatan penulisan ini tentunya tidak terlepas dari campur tangan orang lain untuk itu tidak lupa kami ucapkan banyak terima kasih kepada kedua orang tua kami, istri dan 
anak-anak kami, terutama ibu dan bapak pembimbing dan penguji kami baik yang dikampus maupun yang diluar kampus dan mohon maaf karena tidak dapat kami urutkan namanya satu persatu, jazakallah semoga Allah Swt senantiasa selalau mengucurkan rahmat kepada kita dan membalas seluruh perhatian, dukungan serta sinergitas kita yang telah dibina selama proses penulisan ini berlangsung hingga kami dapat menyelesaikan tesis ini hingga tuntas. Wassalam.

\section{DAFTAR PUSTAKA}

1

2 3

4 5

6 Parkir Menurut Statusnya Sesuai Peraturan Daerah Kota Makassar No.11 tahun 1988

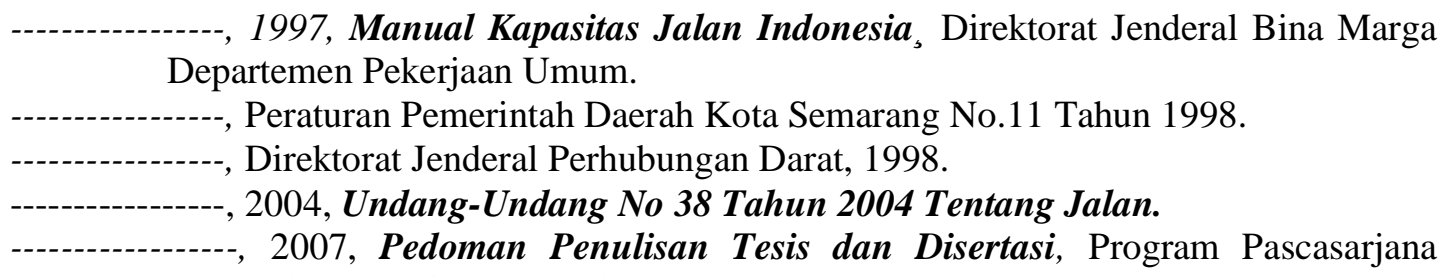
Universitas Muslim Indonesia.

Abdul kadir, Muhammad.'Hukum Pengangkutan Darat, Laut dan Udara', PT. Citra Aditya Bakti, Bandung, 1991.

Alamsyah, Ansyori A, "Rekayasa Lalu-Lintas", UMM Press, Malang, 2005.

Anonymous, 1993 "Indonesian High Capacity Manual, Part I : Urban Roads", Directorat General of Highways Ministry Of Public Works, Jakarta.

Aviasti, "Jurnal TMI", Fakultas Teknik, Penerbit UNISBA, 2004.

Direktorat Bina Sistem Lalu Lintas Dan Angkutan Kota Direktorat Jenderal Perhubungan Darat, "Rekayasa Lalu Lintas”, Jakarta, 1999.

Direktorat Jenderal Perhubungan Darat, "Pedoman Perencanaan dan Pengoperasian Fasilitas Parkir”, Jakarta, 1998.

Edwarsyah,M, "Usulan Tata Letak Fasilitas Parkir Kendaraan Bermotor di UPN Veteran”, Jakarta, 2008.

Hobbs, F.D., 1979. Traffic Planning and Engineering, Second edition, edisi Indonesia, 1995, terjemahan Suprapto T.M. dan Waldijono, Perencanaan dan Teknik Lalu Lintas, Edisi kedua, Gadjah Mada University Press, Yogyakarta.

Tamin Z Ofyar. Perencanaan dan Pemodelan Transportasi, ITB Bandung, 2000.

Khisty, C.Jotin, 2003, Dasar-Dasar Rekayasa Transportasi. Penerbit Erlangga, Jakarta.

Khisty, C.Jotin, 2005, Dasar-Dasar Rekayasa Transportasi. Jilid 1 edisi 3, Penerbit Erlangga, Jakarta.

Khisty, C.Jotin, 2006, Dasar-Dasar Rekayasa Transportasi. Jilid 1 dan 2 edisi 3, Penerbit Erlangga, Jakarta.

Morlok, E. K. 1978. Introduction to Transportation Engineering and Planning. Mc.Graw Hill Kogakuha.

Morlok, E. K. 1988.Introduction to Transport Engineering and Planning di dalamPengantar Teknik dan Perencanaan Transportasi : Johan K. Hainim (Penerjemah) cetakan Tahun 1985. Jakarta : Erlangga.

\section{Jurnal Internasional}


1. Intan Syahrini, 2018, Mathematical Model of Parking Space Unit for Triangular Parking Area, $4^{\text {th }}$ international Conference on Operational Research (interior), Syiah Kuala University, Banda Aceh.

2. Nived K.V, 2017, Coceptualization of LoT Powered Parking System, Int. Journal of Engineering Research and Application Vol 7 Issue 4, Nehru Institute of Engineering and Technology, India.

3. Darabhastu.Bhani, 2017, Design And Implementation of Intteligent Parking System, International Journal of Innovative research in Computer and Communication Engineering vol 5 issue 2, Hyderabad, Telangana, India.

4. Okto Ariansyah, 2017, feasibility review of investment development of parking building, proceeding of international conference, Sultan Agung Islamic University, Semarang, Jawa Tengah.

5. Na Chen, dkk. 2016, Parking Survey Mode Efficient in intelligent Parking Systems, www.sciensedirect.com, Beijing jiatong university, china.

6. Renuka R, 2015, Android Based Smart Parking System Using Slot Allocation \& Reservations, ARPN Journal of Engineering and Applied Sciense Vol.10 No.7, Easwari Engineering College, Chennai, India.

7. Sites Singh, 2015, Study of Parking Patterns for Different Parking Facilities, international journal of civil and structural engineering research vol 2 issue 2, Lovely Professional University, Phagwara Punjab, India.

8. Hee Chian Yee, 2014, Monitoring Parking Space Aviability Via Zigbee Technology, International Journal of Future Computer and Communication Vol.3 No.6, IACST.

9. R. Yusnita Dkk, 2012, intelligent Parking Space Detection System Based on Image Processing, International Journal of innovation Management and Technology Vol.3 no 3.

10. Satish v, 2012, Management of Car Parking System Using wireless Sensor Network, www.ijetae.com vol 2 issue 2, Bhopal, M.P., India. 